\title{
Molecular epidemiology of norovirus in South Korea
}

\author{
Sung-Geun Lee ${ }^{1}$, Han-Gil Cho ${ }^{2}$ E Soon-Young Paik, ${ }^{3, *}$ \\ ${ }^{1}$ Korea Zoonosis Research Institute, Chonbuk National University, Iksan 570-390, ${ }^{2}$ Division of Public Health Research, Gyeonggi Province \\ Institute of Health and Environment, Suwon 440-290, ${ }^{3}$ Department of Microbiology, College of Medicine, The Catholic University of \\ Korea, Seoul 137-701, Korea
}

\begin{abstract}
Norovirus is a major cause of viral gastroenteritis and a common cause of foodborne and waterborne outbreaks. Norovirus outbreaks are responsible for economic losses, most notably to the public health and food industry field. Norovirus has characteristics such as low infectious dose, prolonged shedding period, strong stability, great diversity, and frequent genome mutations. Besides these characteristics, they are known for rapid and extensive spread in closed settings such as hospitals, hotels, and schools. Norovirus is well known as a major agent of food-poisoning in diverse settings in South Korea. For these reasons, nationwide surveillance for norovirus is active in both clinical and environmental settings in South Korea. Recent studies have reported the emergence of variants and novel recombinants of norovirus. In this review, we summarized studies on the molecular epidemiology and nationwide surveillance of norovirus in South Korea. This review will provide information for vaccine development and prediction of new emerging variants of norovirus in South Korea. [BMB Reports 2015; 48(2): 61-67]
\end{abstract}

\section{INTRODUCTION}

Norovirus (NoV) is the major cause of both sporadic cases and reported outbreaks of acute gastroenteritis worldwide, including in South Korea. Up to $93 \%$ of gastroenteritis outbreaks in developed countries are associated with NoV (1). Each year, mortality due to NoV is estimated at $570-800$ in the United States, with approximately $\$ 777$ million in health-care costs. (2) NoV is well known as a major agent of food- and waterborne disease outbreaks associated with acute gastroenteritis worldwide. Particularly, most of the food-catering facilities that use groundwater for preparing food have frequently reported food-poisoning caused by NoV in South Korea. NoV can infect persons of all ages, but predominantly affects young children

${ }^{*}$ Corresponding author. Tel: +82-2-2258-7342; Fax: +82-2-5356477; E-mail: paik@catholic.ac.kr

http://dx.doi.org/10.5483/BMBRep.2015.48.2.254

Received 1 December 2014

Keywords: Epidemiology, Norovirus, Outbreak and the elderly (3). Symptoms of NoV include diarrhea, vomiting, nausea, stomach pain as well as fever, headache and body aches, though NoV infections can also be asymptomatic. Transmission of NoV occurs primarily via direct person-to-person contact, fecal-oral route, and consumption of contaminated food or water (4). In addition, NoV has the following 5 characteristics. First, they have an extremely low infectious dose (18 to 1,000 viral particles). Second, viral shedding continues long after illness. Third, they have strong stability $\left(0\right.$ to $\left.60^{\circ} \mathrm{C}\right)$ in diverse food items and environmental water such as groundwater, recreational and drinking water. Fourth, long-term immunity is nonexistent due to the great diversity of NoV. Finally, the NoV genome mutates frequently by antigenic shifting and recombination. (5). For these reasons, NoV have more rapid and extensive spread in closed settings such as hospitals, hotels, and schools.

A member of the Caliciviridae family, NoV has a positive sense, single-stranded RNA (7.6 kb). The viral RNA genome is divided into three open reading frames (ORFs): ORF1, ORF2, and ORF3. ORF1 encodes nonstructural proteins including $N$ to $\mathrm{C}$ terminus proteins, $\mathrm{p} 48$, NTPase, 3C-like protease, and the highly conserved RNA-dependent RNA polymerase (RdRp). ORF2 encodes a major viral capsid protein VP1, which consists of a shell (S) domain and two protruding (P) domains $(6,7)$. The $\mathrm{P}$ domain is further divided into $\mathrm{P} 1$ and $\mathrm{P} 2$ sub-domains (Fig. 1). Because the P2 sub-domain is located on the surface of the capsid, it has the most hypervariable sequence and contains host-cell binding receptors such as histo-blood group antigens (HBGA) (8). ORF3 encodes a minor capsid protein (VP2). A recombinant virus-like particles (VLPs)-based vaccine study exploiting the self-assembly property of the NoV VP1 protein was previously reported (9). Recently, Katayama et al. reported that they established a reverse genetics system without a helper virus, which successfully produced progeny virus containing infectious genomic RNA (10).

NoV can be divided into 6 genogroups (GI-GVI) and three human NoV genogroups (Gl, Gll, and GIV) (11). Each of the NoV genogroups is further classified into several genotypes. GIl is the predominant genogroup, accounting for over $70 \%$ of NoV Outbreaks. Among them, Gll.4 has been the most frequently identified (12).

The NoV GIl-4 variant appeared on a global scale recently. Gll-4 variants are associated with global gastroenteritis pan-

ISSN: 1976-670X (electronic edition)

Copyright (C) 2015 by the The Korean Society for Biochemistry and Molecular Biology

(c) This is an open-access article distributed under the terms of the Creative Commons Attribution Non-Commercial License (http://creativecommons.org/licenses/by-nc/3.0) which permits unrestricted non-commercial use, distribution, and reproduction in any medium, provided the original work is properly cited. 


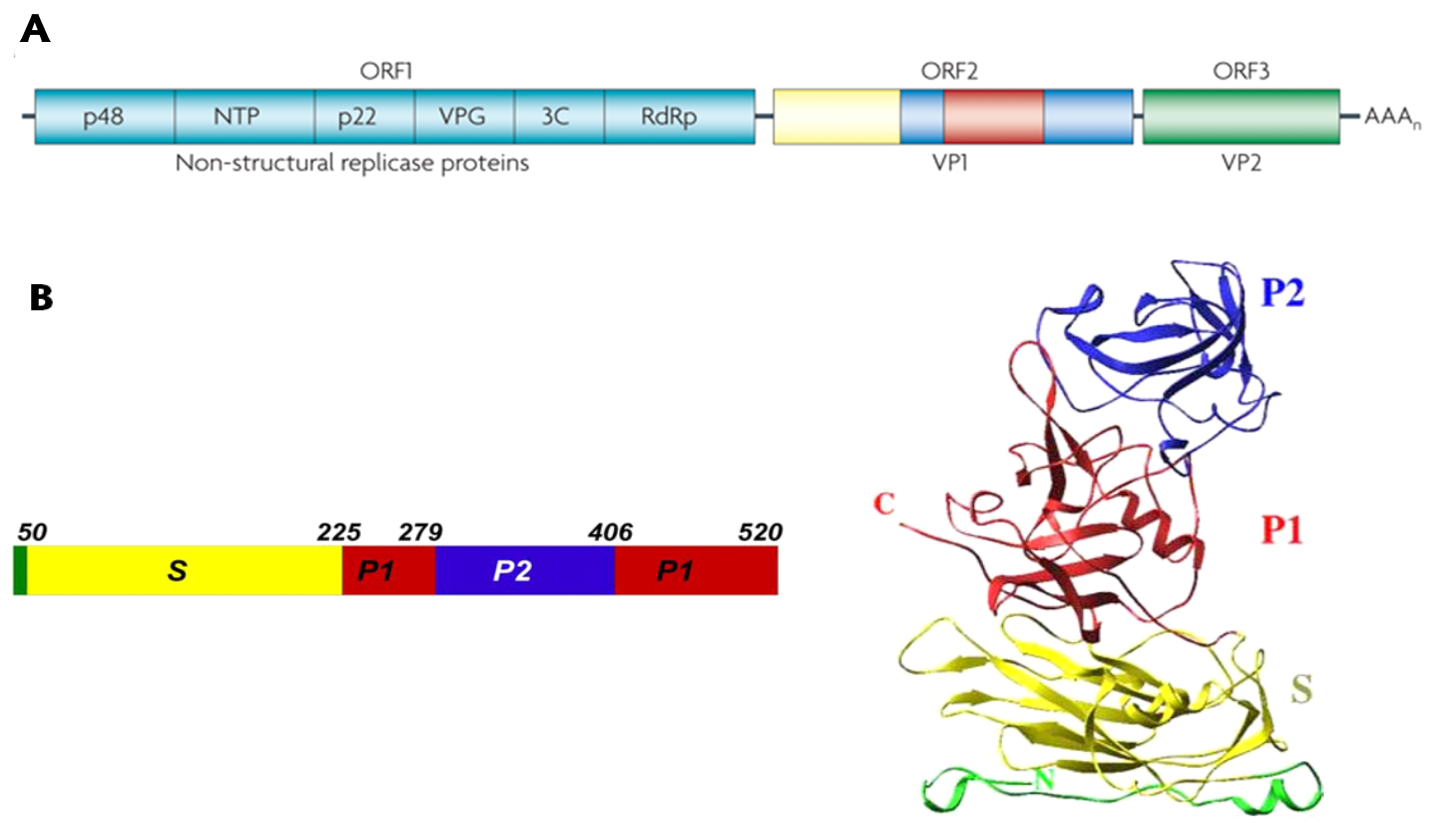

Fig. 1. (A) Norovirus genome organization. (B) VP1 domains and ribbon representation of a VP1 monomer.

demics, and viruses belonging to this genetic lineage account for $>80 \%$ of all NoV outbreaks $(13,14)$. The frequent emergence of novel Gll.4 variants is known to be due to rapid evolution and antigenic variation in response to herd immunity $(15,16)$. Novel Gll-4 variants appear almost every 2 years and their appearance is usually accompanied by a global epidemic associated with acute gastroenteritis. Recent GIl-4 variants have been reported in the following order: Lordsdale 1996, Farmington Hills 2002, Hunter 2004, Yerseke 2006a, Den Haag 2006b, Apeldoorn 2007, New Orleans 2009 and, most recently, Sydney 2012. Particularly, two pandemic variants (New Orleans 2009 and, most recently, Sydney 2012) showed antigenic variation but also recombination at the ORF1/ORF2 region. Novel NoV recombinants have been identified in recent studies worldwide, including in South Korea.

Recombination of NoV is known to occur at the ORF1/ ORF2 region and at the transcription start site for viral subgenomic RNA. Recombination also occurs at the ORF2/ORF3 region in Gll-4 strains, albeit rarely. Recombination within the pandemic NoV Gll-4 Lineage have even been reported in the United States, i.e. New Orleans 2009 (Gll-4 2006a/GIl-4 Apeldoorn 2008-like), Sydney 2012 (Gll-4 Osaka 2007/GIl-4 Apeldoorn 2008-like), and Japan 2008b (Gll.4 Apeldoorn 2008/GIl.4 2006b) in ORF1/ORF2 region (17). Data from 2010 to 2013 showed that diverse inter- and intragenotype NoV recombinants were identified in South Africa. They were identified as Gll-P21/GIl-3, GIl-P NA/GIl-3, Gll-P4 New Orleans 2009/Gll-4 NA， Gll-Pg/Gll-1， Gll-P16/GIl-17, GIl-Pe/GIl-4 Osaka 2007, GII-P21/GIl-2, GIl-P4 New Orleans 2009/GIl-4
Sydney 2012, GII-Pg/GIl-12, GII-Pe/Sydney 2012, and GII-P7/ Gll-6 (18). Data from 2010 to 2012 showed that novel recombinants, GII-P22/GII-5 and GIl-21/GIl-3, were identified in China (19).

In South Korea, NoV is well known as a major agent of acute gastroenteritis and food/ waterborne diseases. Annually, hundreds of outbreaks associated with food - waterborne diseases are reported by the national surveillance system (20). Furthermore, studies on molecular epidemiology have gradually increased in South Korea since 2005. In this review, we described diverse studies focusing on the molecular epidemiology of NoV in South Korea.

\section{HUMAN NoV INFECTIONS}

The large scale molecular epidemiology study of human NoVs in South Korea published in 2008 was the first ever reported. NoV infections were detected in 114 of 762 (15\%) children with acute gastroenteritis at eight domestic hospitals in South Korea between November 2005 and November 2006. Twelve $\mathrm{GI}$ NoVs from a total of $114 \mathrm{NoVs}$ were further classified into only one genotype, Gl-6, accounting for $10.5 \%$ (12 of 114). The remaining 102 Gll NoVs were classified into Gll-2, GIl-3, Gll-4, Gll-5, Gll-6, and Gll-8, accounting for 0.9\% (1 of 114), $7.9 \%$ (9 of 114 ), $71.9 \%$ (82 of 114 ), $5.3 \%$ (6 of 114 ), $1.8 \%$ (2 of 114 ), and $0.9 \%$ (1 of 114 ), respectively. Among them, Gll-4 was the most frequent genotype $(71.9 \%)(21)$. The molecular epidemiologies of human NoVs from regional units in South Korea have been steadily reported since 2008. Data from 2001 
to 2005 showed that NoV accounted for $12.6 \%$ of 2,908 patients infected with a virus hospitalized with acute gastroenteritis in Gyeonggi province (22). Between March 2008 and March 2011, NoV infections were detected in 710 of 7,002 $(10.1 \%)$ children with acute gastroenteritis in Seoul. Of these, 27 of the $710(3.8 \%)$ specimens were determined to belong to $\mathrm{Gl}$, and 683 of the 710 specimens belonged to Gll. Ten GI genotypes $(\mathrm{Gl} / 1, \mathrm{Gl} / 2, \mathrm{Gl} / 3, \mathrm{Gl} / 4, \mathrm{Gl} / 5, \mathrm{Gl} / 6, \mathrm{Gl} / 7, \mathrm{Gl} / 9, \mathrm{Gl} / 12$, and $\mathrm{Gl} / 13$ ) and eight Gll genotypes (GII/2, GIl/3, Gll/4, GII/8, Gll/14, Gll/15, Gll/16, and Gll/17) were identified. Among them, Gll-4 was the most frequent genotype (74.5\%) (23).

Data from 2007 to 2010 showed that NoV accounted for $13 \%$ of 11,219 patients infected with a virus hospitalized with acute gastroenteritis in 5 hospitals in 3 regions (Seoul, Gyeonggi province, Gangwon province). The positive rates of NoVs were $16.2 \%, 13.8 \%$, and $9.9 \%$ in 2007,2008 , and 2009 , respectively, demonstrating a declining trend annually (24). It was presumed that the positive rate decline was associated with improved hygiene following the pandemic flu in 2009. More recent data has shown NoV-positive rates of $9.7 \%$ for children with acute diarrhea hospitalized at Iksan hospital in 2010-2011 (25).

\section{SEASONALITY}

NoV infection is well known to occur mainly in the winter season. In South Korea, the seasonality of NoV peaked in December, March, and October between 2005 and 2006 (Fig.

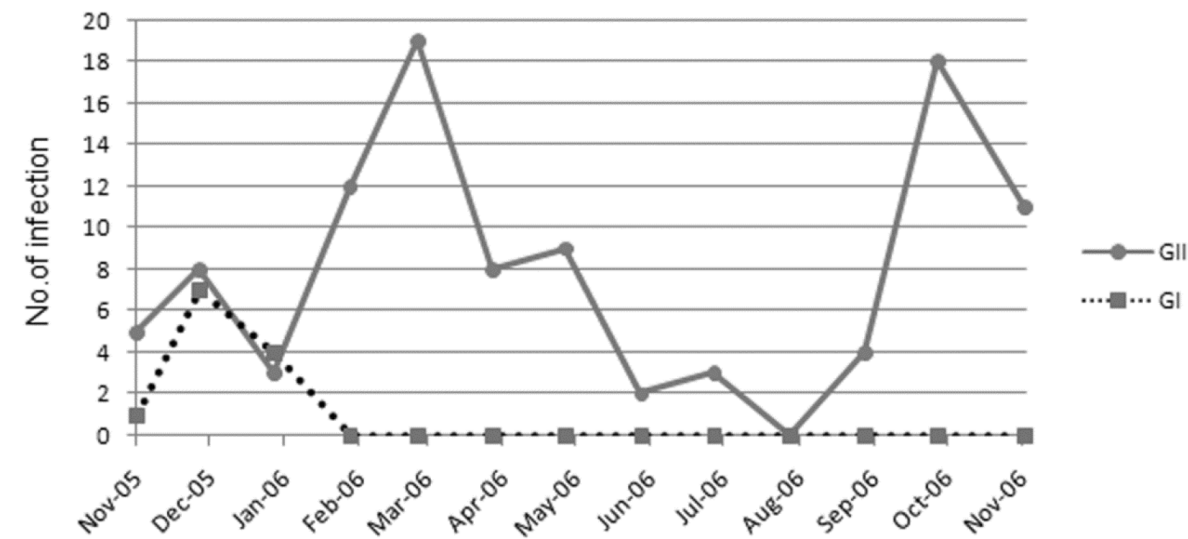

Fig. 2. Seasonality of $\mathrm{Gl}$ and GII NoV infections in South Korea, November 2005 to November 2006.

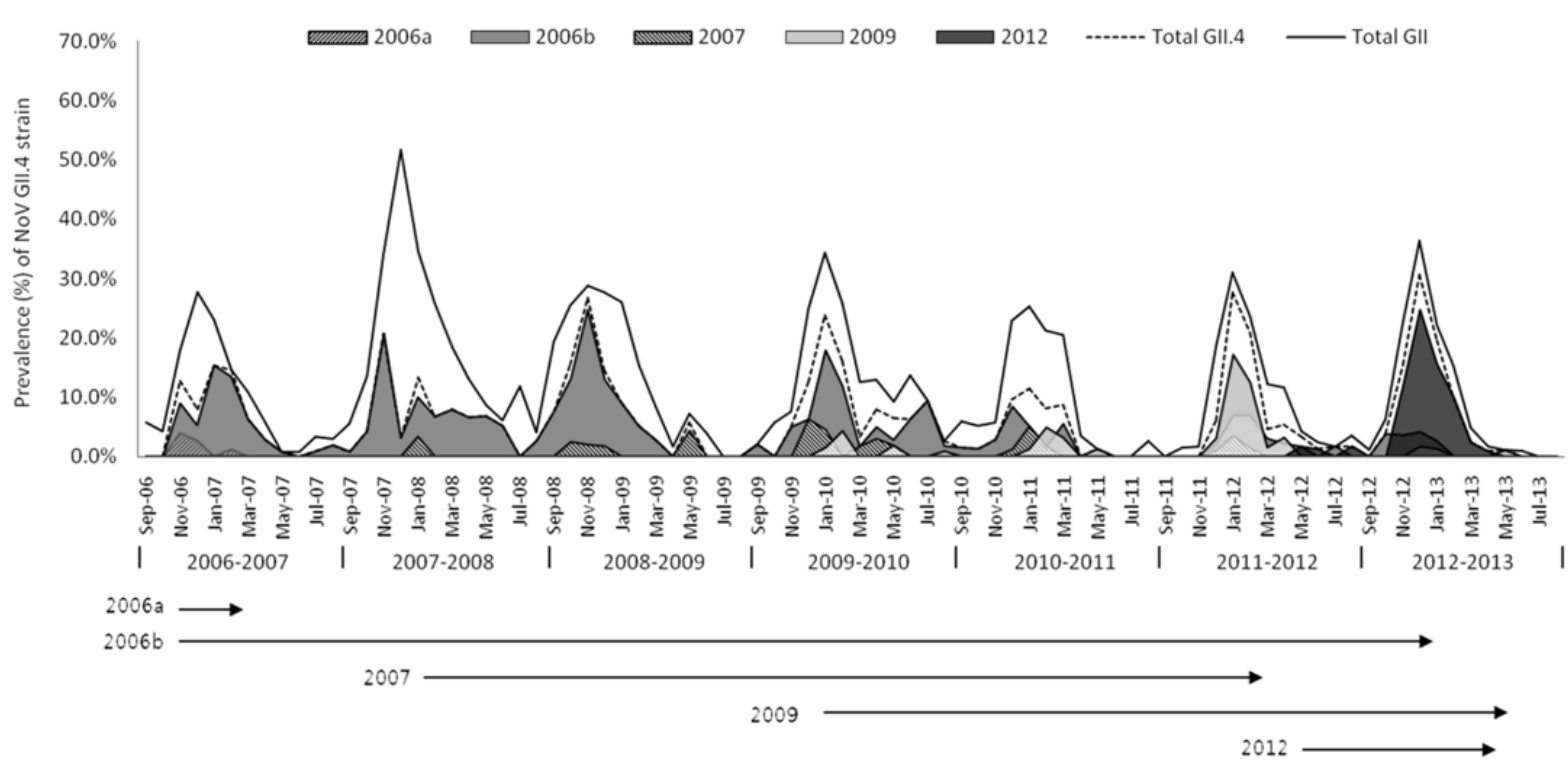

Fig. 3. Epidemic changes of Gll.4 variants detected in children with sporadic acute gastroenteritis in Gyeonggi province, South Korea, from 2006-2007 to 2012-2013. 
2). Data from 2007 to 2008 showed that the incidence of NoV was highest in November, followed by January and October (26). Park et al. also reported similar results; the seasonality of NoV peaked in November between 2007 and 2010, with the exception of 2009 (24). According to a recent study, the seasonality of NoV in South Korea between 2006 and 2013 peaked during the winter months, such as November to January (Fig. 3).

\section{FOOD-BORNE OUTBREAK AND SPORADIC CASES}

NoV is the leading cause of food-borne outbreaks worldwide $(2,20,27)$. These food-borne outbreaks are associated with consumption of food contaminated by NoV. Particularly, the occurrence of food-borne outbreaks in closed settings such as schools and cruise ships demonstrates the high attack rate (28). Food-catering facilities have frequently reported food-poisoning caused by NoV in South Korea. An outbreak of gastroenteritis occurred in elementary schools in Incheon in 2008. $7.5 \%(117 / 1,560)$ of individuals who ate food from the school cafeteria were symptomatic cases. Statistical analyses results showed that consumption of cucumber-crown daisy salads, fresh cabbage mixes, dried radish salads and young radish kimchi were associated with illness. Sixty-four of 142 people who provided stool samples were positive for NoV (45\%). The NoV genotypes in those individuals were all Gll-4, except for 1 student. There was no evidence of infection from food or water consumption. Based on an epidemiological survey, $\mathrm{Yu}$ et al. concluded that food handlers previously infected with NoV may be an infection source for outbreaks (29).

According to a previous study by Yu et al, 3.4\% (26/776) of asymptomatic food handlers were positive for NoV in elementary schools with no NoV outbreaks. The study revealed that the infection source for NoV outbreaks may be related to asymptomatic food handlers (30). Jeong et al. also reported similar results. Between February 2009 and February 2010, $1.2 \%(66 / 6,441)$ of asymptomatic food handlers were positive for NoV in food catering facilities in South Korea. The genotypic distribution of the NoV strains was as follows: Gll-12, Gll-4, Gll-2, Gll-6, Gll-11, Gll-14, Gl-1, and Gl-12. The detection rate of asymptomatic infections in the winter and non-winter was $2.20 \%$ and $0.16 \%$, respectively. The study also concluded that NoV infected but asymptomatic food handlers were an important transmission source (31). These results showed that asymptomatic or symptomatic food handlers are closely related to NoV food borne outbreaks. According to a recent study, a successive outbreak of gastroenteritis was reported in two different schools. Statistical analyses showed that seasoned green seaweed with radishes was significantly associated with the illness. The green seaweed used by both schools came from the same company, located in Busan. The infection rate at the schools were $6.7 \%(60 / 936)$ and $5.4 \%$ (31/574), respectively. Phylogenetic analysis revealed that the NoV Gll-6 genotype in both outbreaks was indistinguishable.
Samples were obtained from the company that provided the green seaweed and the seawater used for washing was positive for NoV GIl.4. However, there was no evidence of consumption of contaminated drinking water or cooking water in both schools. Hence, Park et al. suggested that only consumption of uncooked green seaweed could explain these NoV outbreaks (32).

\section{WATER-BORNE OUTBREAK AND SPORADIC CASES}

Water-borne NoV outbreaks in South Korea were first reported in 2005. Ninety-seven out of $309(31 \%)$ and 97 out of 207 $(47 \%)$ students were affected by acute gastroenteritis during school excursions in 2004. Afterward, Kim et al. conducted an epidemiological and virological survey. Several NoV genotypes were isolated from clinical and environmental samples. Of these genotypes, one was identified in samples obtained from the students, food handlers, and from groundwater. Based on the results of the molecular epidemiological survey, the researchers concluded that the two outbreaks were caused by several NoV strains which were closely related with contaminated groundwater (33). In January 2008, an outbreak of gastroenteritis caused by NoV-contaminated groundwater occurred in a waterpark in Sunngnam, Gyeonggi-do. Sixty-seven out of $216(31.0 \%)$ students and teachers were affected by acute gastroenteritis. Statistical analyses showed that food items were not associated with the illness. NoV was detected in both clinical and groundwater samples from the waterpark. In nucleotide sequencing analysis, all the NoV Gl from the clinical and groundwater samples were identified as the NoV Gl-4 strain. Hence, Koh et al. concluded that the NoV outbreak was closely related to the contaminated groundwater (34).

Consecutive gastroenteritis outbreaks were reported at schools in 3 regions (Suwon, Yong-In, Gwang-Ju) within Gyeonggi-do in 2011. 451 out of 7,605 were symptomatic cases, for an infection rate of $5.9 \%$. Among the 239 stool specimens collected from students and food handlers, $59(24.7 \%)$ were confirmed as infected with NoVs using RT-PCR and nucleotide sequence analysis. All NoV genotypes were Gl-3 except for 1 food handler, whose NoV genotype was Gll-18. Epidemiological survey revealed that the kimchi used by 5 of the affected schools came from the same food-company. Groundwater close to the food-company and groundwater used for food manufacturing were positive for NoV Gl. The sequence similarity between the specimens from patients and those from the groundwater samples was $100 \%$. The study concluded that there should be extensive control and management of groundwater facilities and groundwater used for food manufacturing (35). Data from 2012 showed that NoV accounted for $75.9 \%$ of 29 patients and $74.5 \%$ of 102 patients with acute gastroenteritis at 2 restaurants in Gyeonggi province, respectively. NoV was also detected in both clinical and environmental samples (Camp groundwater and Tap-water). Epidemiological surveys revealed 
that both outbreaks were closely related with consumption of meals prepared using groundwater or with drinking groundwater. NoVs identified in the two cases were GIl-17 and GIl-2, respectively. The sequence similarity between the specimens from clinical and groundwater samples was $96.6-100 \%$ (36).

\section{NATIONWIDE SURVEY FOR NoV}

Large scale food-borne outbreaks associated with NoVs occurred in school catering service facilities in South Korea in 2006. These outbreaks were suspected to be caused by NoV contaminated groundwater. Since then, extensive nationwide surveys have been conducted at facilities that use groundwater or raw-groundwater. In 2008, Lee et al. reported a nationwide study on NoV contamination in South Korean groundwater. In accordance with the seasonal pattern of $\mathrm{NoV}$, groundwater samples from 300 sites were collected in the summer (June to August) and winter (October to December) from seven metropolitan areas along with the capital, and nine provinces in South Korea. NoV detection rates were $21.7 \%$ (65/300) in summer and $17.3 \%$ (52/300) in winter. Genetic analyses of the detected NoV showed that there were more varieties of $\mathrm{NoV}$ genotypes in the summer (Gl-1, Gl-2, Gl-3, Gl-4, Gl-5, Gl-6, Gl-8 and Gll-4 and Gll-Yuri) than in winter (Gl-1, Gl-3, Gl-4, Gl-5 and GII-4 and GII-Yuri). Lee at al. concluded that this might be due to specific climate conditions in South Korea, such as torrential rains in the summer. Among the detected genotypes, Gll-4 was the most frequent in both summer (44 detections, 58.7\%) and winter (30 detections, 47.6\%) (37).

Between 2009 and 2011, extensive nationwide surveys were conducted at school catering service facilities by the KFDA (Ministry of Food and Drug Safety). Kim and colleagues inspected the NoV contamination levels of groundwater treatment systems used in school catering service facilities located in South Korea in 2009. Among the 813 samples collected, seven $(0.86 \%)$ were positive for NoVs. The $7 \mathrm{NoV}$ s were classified into 3 genotypes: Gl-6, Gl-8, Gll-3, and Gll-4. A follow up study was performed after the 2009 study. According to the study by Lee et al., among the 1,090 samples obtained, seven $(0.64 \%)$ were positive for NoVs. The $7 \mathrm{NoV}$ s were classified into 5 genotypes: Gl-6, GIl-ND, Gll-3, Gll-4, and Gll-17. To explain the low detection rate at school catering service facilities, Lee et al. suggested that there are at least two possible reasons. 1) Steady management and preventative care of groundwater storage tanks. 2) The tested samples were not untreated groundwater, i.e. raw groundwater (38). Data from 2013 showed that NoVs accounted for $0.05 \%$ of 1,200 groundwater samples near carcass burial sites in South Korea in 2010 (39).

\section{EMERGENCE OF RECOMBINANT NoV STRAINS}

Recombinant NoV strains were first reported in South Korea in 2010. Data from 2007 to 2008 showed that $10 \%$ of the 111 GIl-4 strains were identified as recombinant (GIl-4/GIl-3 and
GII-b/GIl-16) in children hospitalized with acute gastroenteritis in Seoul (26). In a follow up study, Han et al. revealed that non-GIl-4 recombinant NoV strains such as Gll-6/GIl-7, GII-ND/ Gll-12, Gll-b/Gll-13, Gll-6/Gll-14, Gll-b/16 co-circulated between 2008 and 2010 (40). Recently, a Gll-12/GIl-13 recombinant strain was isolated from one child under 5 years of age who had gastroenteritis (41).

\section{EMERGENCE OF NoV GII-4 VARIANTS}

Gll-4 variants have caused major NoV outbreaks worldwide since 1996. These Gll-4 variant outbreaks include Lordsdale 1996, Farmington Hills 2002, Hunter 2004, Yerseke 2006a, Den Haag 2006b, Apeldoorn 2007, New Orleans 2009 and, most recently, Sydney 2012. A GIl-4 variant was first reported in South Korea in 2010. Data from 2007 to 2008 showed that most of the Gll-4 strains in Seoul and Jeju Island were identified as the Gll-4 2006b variant, with $97.9-100 \%$ nucleotide identity $(39,42)$. A follow up study has been performed since. Data from 2008 to 2010 revealed that a change in the Gll-4 $2006 \mathrm{~b}$ variant yielded the 2008 variant (40). Park et al. also reported that 3 Gll-4 variants (2006b, 2008, 2010) co-circulated in Chungnam in Korea between 2008 and 2010 (43, 44). Recently, a study on the annual prevalence of GIl-4 variants between 2006 and 2013 was performed by Cho et al. They found that the Gll.4-2006b variant predominated between 2006 and 2010 and persisted in other periods. The Gll.4-2009 variant was first detected in January 2010 and was predominant in 2011-2012. However, it was rapidly displaced by the Gll.4-2012 variant, which emerged in May 2012 and circulated substantially in 2012-2013 (45). According to a recent study, Gll-2006b variants were still co-circulating with 2012 variants in November 2012 and June 2013 in South Korea (46).

\section{CONCLUSIONS}

NoV is the major cause of acute gastroenteritis related to food and waterborne outbreaks and sporadic cases appear worldwide including in South Korea. Economic losses caused by NoV outbreaks have been increasing annually in South Korea. In this review, we summarized studies that were based on nationwide surveillance and molecular epidemiological data of NoV outbreaks in South Korea. The results of the studies were similar to others reported worldwide such as the genotypic distribution and emergence of variant and novel recombinants. Public concerns regarding NoV have recently increased worldwide. Therefore, we suggest understanding the transmission route of NoV using molecular epidemiological surveys and intensive nationwide surveys conducted under diverse clinical and environmental situations. This review will provide information for vaccine development and prediction of new emerging variants of NoV by comparing molecular epidemiological studies from overseas countries with those in South Korea. 


\section{ACKNOWLEDGEMENTS}

This study was supported by the National Research Foundation of Korea (5-2012-A0154-00218).

\section{REFERENCES}

1. Patel MM, Hall AJ, Vinjé J and Parashar UD (2009) Noroviruses: a comprehensive review. J Clin Virol 44, 1-8

2. Hall AJ, Wikswo ME, Pringle K, Gould LH and Parashar UD (2014) Vital signs: foodborne norovirus outbreaks United States, 2009-2012. MMWR Morb Mortal Wkly Rep 63, 491-495

3. Hall AJ, Lopman BA, Payne DC et al (2013) Norovirus disease in the United States. Emerg Infect Dis 19, 1198-1205

4. Hall AJ, Vinje J, Lopman B et al (2011) Updated norovirus outbreak management and disease prevention guidelines. MMWR Morb Mortal Wkly Rep 60, 1-15

5. Glass RI, Parashar UD and Estes MK (2009) Norovirus gastroenteritis. N Engl J Med 361, 1776-1785

6. Hardy ME (2005) Norovirus protein structure and function. FEMS Microbiol Lett 253, 1-8

7. Katayama K, Murakami K, Sharp TM et al (2014) Plasmidbased human norovirus reverse genetics system produces reporter-tagged progeny virus containing infectious genomic RNA. Proc Natl Acad Sci U S A 111, E4043-E4052

8. Tan $M$ and Jiang X (2005) The p domain of norovirus capsid protein forms a subviral particle that binds to histo-blood group antigen receptors. J Virol 79, 14017-14030

9. Donaldson EF, Lindesmith LC, Lobue AD and Baric RS (2010) Viral shape-shifting: norovirus evasion of the human immune system. Nat Rev Microbiol 8, 231-241

10. Thorne LG and Goodfellow IG (2014) Norovirus gene expression and replication. J Gen Virol 95, 278-291

11. Caddy S, Breiman A, le Pendu J and Goodfellow I (2014) Genogroup IV and VI canine noroviruses interact with histo-blood group antigens. J Virol 88, 10377-10391

12. Fankhauser RL, Monroe SS, Noel JS et al (2002) Epidemiologic and molecular trends of "Norwalk-like viruses" associated with outbreaks of gastroenteritis in the United States. J Infect Dis 186, 1-7

13. Hasing ME, Lee BE, Preiksaitis JK et al (2013) Emergence of a new norovirus Gll.4 variant and changes in the historical biennial pattern of norovirus outbreak activity in Alberta, Canada, from 2008 to 2013. J Clin Microbiol 51, 2204-2211

14. Vega E, Barclay L, Gregoricus N, Shirley SH, Lee D and Vinjé J (2014) Genotypic and epidemiologic trends of norovirus outbreaks in the United States, 2009 to 2013. J Clin Microbiol 52, 147-155

15. Lindesmith LC, Beltramello M, Donaldson EF et al (2012) Immunogenetic mechanisms driving norovirus Gll.4 antigenic variation. PLoS Pathog 8, e1002705

16. Siebenga JJ, Lemey P, Kosakovsky Pond SL et al (2010) Phylodynamic reconstruction reveals norovirus Gll.4 epidemic expansionsand their molecular determinants. PLoS Pathog 6, e1000884

17. Eden JS, Tanaka MM, Boni MF, Rawlinson WD and White PA (2013) Recombination within the pandemic norovirus
Gll.4 lineage. J Virol 87, 6270-6282

18. Mans J, Murray TY and Taylor MB (2014) Novel norovirus recombinants detected in South Africa. Virol J 11, 168

19. Jia LP, Qian Y, Zhang Y et al (2014) Prevalence and genetic diversity of noroviruses in outpatient pediatric clinics in Beijing, China 2010-2012. Infect Genet Evol 28, 71-77

20. Moon S, Sohn IW, Hong Y et al (2014) Emerging Pathogens and Vehicles of Food- and Water-borne Disease Outbreaks in Korea, 2007-2012. Osong Public Health Res Perspect 5, 34-39

21. Yoon JS, Lee SG, Hong SK et al (2008) Molecular epidemiology of norovirus infections in children with acute gastroenteritis in South Korea in November 2005 through November 2006. J Clin Microbiol 46, 1474-1477

22. Huh JW, Kim WH, Moon SG, Lee JB and Lim YH (2009) Viral etiology and incidence associated with acute gastroenteritis in a 5-year survey in Gyeonggi province, South Korea. J Clin Virol 44, 152-156

23. Park S, Jung J, Oh S et al (2012) Characterization of norovirus infections in Seoul, Korea. Microbiol Immunol 56, 700-707

24. Park DJ, Kim JS, Park JY et al (2010) Epidemiological Analysis of Norovirus Infection between March 2007 and February 2010. Korean J Lab Med 30, 647-653

25. So CW, Kim DS, Yu ST, Cho JH and Kim JD (2013) Acute viral gastroenteritis in children hospitalized in Iksan, Korea during December 2010-June 2011. Korean J Pediatr 56, 383-388

26. Chung JY, Han TH, Park SH, Kim SW and Hwang ES (2010) Detection of Gll-4/2006b variant and recombinant noroviruses in children with acute gastroenteritis, South Korea. J Med Virol 82, 146-152

27. Mayet A, Andreo V, Bedubourg G et al (2011) Food-borne outbreak of norovirus infection in a French military parachuting unit, April 2011. Euro Surveill 16, 19930

28. Vivancos R, Keenan A, Sopwith W et al (2010) Norovirus outbreak in a cruise ship sailing around the British Isles: investigation and multi-agency management of an international outbreak. J Infect 60, 478-485

29. Yu JH, Kim NY, Koh YJ and Lee HJ (2010) Epidemiology of foodborne Norovirus outbreak in Incheon, Korea. J Korean Med Sci 25, 1128-1133

30. Yu JH, Kim NY, Lee EJ and Jeon IS (2011) Norovirus infections in asymptomatic food handlers in elementary schools without norovirus outbreaks in some regions of Incheon, Korea. J Korean Med Sci 26, 734-9

31. Jeong AY, Jeong HS, Lee JS et al (2013) Occurrence of norovirus infections in asymptomatic food handlers in South Korea. J Clin Microbiol 51, 598-600

32. Park JH, Jeong HS, Lee JS et al (2014) First norovirus outbreaks associated with consumption of green seaweed (Enteromorpha spp.) in South Korea. Epidemiol Infect 27, $1-7$

33. Kim SH, Cheon DS, Kim JH et al (2005) Outbreaks of gastroenteritis that occurred during school excursions in Korea were associated with several waterborne strains of norovirus. J Clin Microbiol 43, 4836-4839

34. Koh SJ, Cho HG, Kim BH and Choi BY (2011) An outbreak of gastroenteritis caused by norovirus-contaminated groundwater at a waterpark in Korea. J Korean Med Sci 
26, 28-32

35. Lee MJ, Kim WH, Cho HG and Lee SS (2012) Epidemiological Study of Ground-waterborne Norovirus Gl.3-associated Gastroenteritis Outbreaks in Gyeonggi Province of South Korea in May 2011. J Bacteriol Virol 42, 232-241

36. Cho HG, Lee SG, Kim WH et al (2014) Acute gastroenteritis outbreaks associated with ground-waterborne norovirus in South Korea during 2008-2012. Epidemiol Infect 142, 2604-2609

37. Lee SG, Jheong $\mathrm{WH}$, Suh $\mathrm{Cl}$ et al (2011) Nationwide groundwater surveillance of noroviruses in South Korea, 2008. Appl Environ Microbiol 77, 1466-1474

38. Lee BR, Lee SG, Park JH et al (2013) Norovirus contamination levels in ground water treatment systems used for food-catering facilities in South Korea. Viruses 5, 16461654

39. Joung HK, Han SH, Park SJ et al (2013) Nationwide surveillance for pathogenic microorganisms in groundwater near carcass burials constructed in South Korea in 2010. Int J Environ Res Public Health 10, 7126-7143

40. Han $\mathrm{TH}$, Kim $\mathrm{CH}$, Chung JY, Park $\mathrm{SH}$, and Hwang ES (2011) Emergence of norovirus Gll-4/2008 variant and recombinant strains in Seoul, Korea. Arch Virol 156, 323-
329

41. Won YJ, Park JW, Han SH et al (2013) Full-genomic analysis of a human norovirus recombinant Gll.12/13 novel strain isolated from South Korea. PLoS One 8, e85063

42. Le VP, Jung YC, Kang KS, Lim I, Myung SC and Kim W (2010) Genetic characterization of norovirus Gll.4 2006b variants from Jeju island, South Korea. J Med Virol 82, 1065-1070

43. Park KS, Jeong HS, Baek KA et al (2010) Genetic analysis of norovirus Gll.4 variants circulating in Korea in 2008. Arch Virol 155, 635-641

44. Park K, Yeo S, Jeong H et al (2012) Updates on the genetic variations of norovirus in sporadic gastroenteritis in Chungnam Korea, 2009-2010. Virol J 9, 29

45. Cho HG, Lee SG, Kim JE et al (2014) Molecular epidemiology of norovirus Gll.4 variants in children under 5 years with sporadic acute gastroenteritis in South Korea during 2006-2013. J Clin Virol 61, 340-344

46. Kim HS, Hyun J, Kim HS, Kim JS, Song W and Lee KM (2013) Emergence of Gll.4 Sydney norovirus in South Korea during the winter of 2012-2013. J Microbiol Biotechnol 23, 1641-1643 